\title{
Direct measurement of crystal surface stress
}

\section{Citation}

Martinez, Robert, Walter Augustyniak, and Jene Golovchenko. 1990. Direct Measurement of Crystal Surface Stress. Physical Review Letters 64, no. 9: 1035-1038. doi:10.1103/ physrevlett.64.1035.

\section{Published Version}

doi:10.1103/PhysRevLett.64.1035

\section{Permanent link}

http://nrs.harvard.edu/urn-3:HUL.InstRepos:29407034

\section{Terms of Use}

This article was downloaded from Harvard University's DASH repository, and is made available under the terms and conditions applicable to Other Posted Material, as set forth at http:// nrs.harvard.edu/urn-3:HUL.InstRepos:dash.current.terms-of-use\#LAA

\section{Share Your Story}

The Harvard community has made this article openly available.

Please share how this access benefits you. Submit a story.

Accessibility 


\title{
Direct Measurement of Crystal Surface Stress
}

\author{
Robert E. Martinez, ${ }^{(1)}$ Walter M. Augustyniak, ${ }^{(1)}$ and Jene A. Golovchenko ${ }^{(1,2)}$ \\ (1)Lyman Laboratory of Physics, Harvard University, Cambridge, Massachusetts 02138 \\ ${ }^{(2)}$ Rowland Institute for Science, Cambridge, Massachusetts 02142
}

(Received 14 September 1989)

\begin{abstract}
We have measured surface stresses on clean $\mathrm{Si}(111) 7 \times 7$ by comparing this surface to a reference surface on which gallium atoms are adsorbed under UHV conditions. Stresses are determined by optically measuring the macroscopic strain induced in thin samples. We find a surface stress of 2.37 $\mathrm{eV} /(1 \times 1$ cell $)$ for $\mathrm{Si}(111) 7 \times 7$, and a stress in the range $0.90-1.09 \mathrm{eV} /(1 \times 1$ cell) for the $\mathrm{Si}(\mathrm{Ga})(111)$ superlattice associated with one-monolayer Ga coverage. Comparison with theory suggests that our technique will be a powerful tool to measure equilibrium stresses in atomically clean surfaces.
\end{abstract}

PACS numbers: $68.35 . G y$, 68.35.Md, 68.55.Gi

Recent experiments have illustrated the importance of surface stress in determining reconstructions at semiconductor surfaces. Experiments done on $\mathrm{Si}(111)$ and Ge(111) surfaces have shown that both strained-layer film growth and alloying can generate new reconstructions in these surfaces by effectively straining the surface region. ${ }^{1,2}$ Another example of the role stresses can play in determining surface reconstruction is provided by the experiments of Men, Packard, and Webb, ${ }^{3}$ in which $\mathrm{Si}(100) 2 \times 1$ and $1 \times 2$ reconstruction domains were seen to vary in relative prevalence as a function of applied strain. Local-density-approximation (LDA) calculations have also been performed recently to determine equilibrium surface energies and stresses for various phases of clean and chemisorbed $\mathrm{Si}(111)$ and $\mathrm{Ge}(111)$ surfaces. $^{4-6}$

While the experiments of Refs. 1-3 have examined strain-induced surface modifications, none of them have measured the intrinsic stress associated with equilibrium surfaces, which can be compared with theory. In this paper we present what we believe to be the first direct measurement of induced surface stresses on atomically clean surfaces. We discuss the choice of a fiducial surface to make absolute surface-stress determinations, and, where possible, compare our results with theoretical predictions.

The principle of our experimental technique is straightforward. A thin sample, prepared with opposite faces having different surface stresses, should bend as a result of the stress difference. The bending can be measured optically (Fig. 1) and is related to the surfacestress difference by continuum elasticity theory, as will be discussed later. An optical technique to measure stresses in thin metallic and dielectric films was first employed by Ennos in a study of optical coatings. ${ }^{7}$ More recently, optical methods have been used to measure stresses in thin metallic films ${ }^{8}$ and oxides ${ }^{9}$ grown on silicon. However, we know of no other measurements of surface stresses related to chemical and structural phenomena in the first atomic layer of an atomically clean sample.
The samples used in these experiments were prepared from $p$-type, B-doped (1850-1950 $\Omega \mathrm{cm}$ ) float-zonerefined $\mathrm{Si}(111)$, Syton polished on both sides to 0.004 in. thickness by Pensilco, from material produced by Wacker. They were shaped as illustrated in Fig. 1 and cleaned by the Shiraki-etch procedure. ${ }^{10}$ The experiments were carried out in a UHV chamber (base pressure $2 \times 10^{-10}$ Torr) containing a LEED apparatus and a Ga effusion cell. The sample was mounted to leave both sides of its broad section $\left(2.5 \times 0.3 \mathrm{~cm}^{2}\right)$ exposed. The sample could be rotated $180^{\circ}$ about its vertical axis, allowing us to make depositions of $\mathrm{Ga}$ on either side, and to check the structure of each surface using LEED.

To measure the bending of the sample, two incident $\mathrm{He}-\mathrm{Ne}$ laser beams, separated by $L=2.2 \mathrm{~cm}$, were reflected from the ends of the sample at near-normal incidence. The reflected beams were monitored with a split photodiode detector ${ }^{11}$ located $D=2.88 \mathrm{~m}$ from the sample. The detector was mounted on a micrometerdriven linear translation stage. The position of each reflected beam was recorded and the beam separation, $X$,

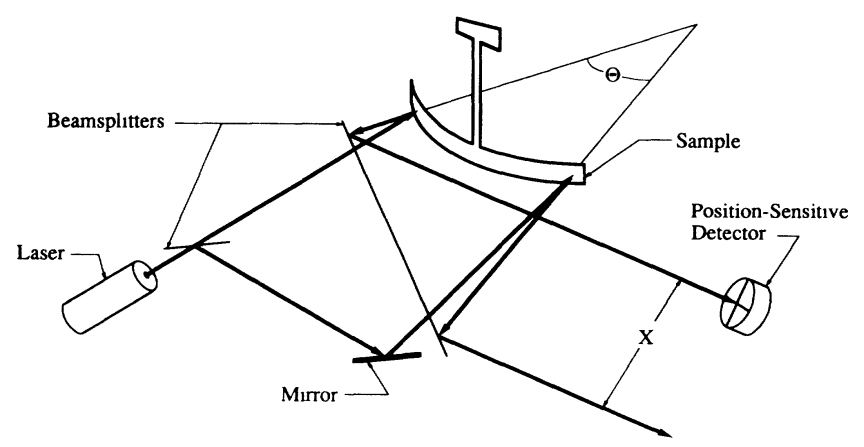

FIG. 1. Schematic illustration of the surface-stress measurement system. $X$ is the measured beam separation. The broad section of the sample has dimensions $2.5 \times 0.3 \mathrm{~cm}^{2}$, the vertical "neck" is $0.25 \mathrm{~cm}$ wide by $1.6 \mathrm{~cm}$ long, and the overall height is $2.5 \mathrm{~cm}$. The gallium-adsorbed side of the sample is facing the reader. 
was measured as the difference of these. Changes in $X$ after $\mathrm{Ga}$ deposition were related to changes in the angle $\Theta$ between surface normals where reflection occurred by

$$
\Delta \theta=\Delta X / 2 D \text {. }
$$

Angular changes as small as $2.5 \mu$ rad could be measured, corresponding to an induced radius of curvature of $10 \mathrm{~km}$ in an initially flat sample. The bending of the crystal determined by $\Delta \theta$ was then related to the surface-stress difference between the two sides of the sample by

$$
\sigma(\text { front })-\sigma(\text { rear })=-\Delta \theta E h^{2} / 6(1-v) L,
$$

derived from continuum elasticity theory. ${ }^{8,12}$ Here, $h$ is the sample's thickness, and $E$ and $v$ are Young's modulus and the Poisson ratio of the sample, respectively. Positive stresses are tensile. The "front" of the sample is the side from which the light beams are reflected. For $\mathrm{Si}(111), 1 \mathrm{eV} /(1 \times 1$ cell $)=1253 \mathrm{dyn} / \mathrm{cm}$ and the elastic coefficient $E /(1-v)$ has the value $2.29 \times 10^{12}$ $\mathrm{dyn} / \mathrm{cm}^{2}$ for directions within Si $\{11\}$ planes. ${ }^{13}$ Note that the stress measurements have an uncertainty of $\pm 0.05 \mathrm{eV} /(1 \times 1$ cell $)$ due to uncertainties in the optical measurements.

Our samples were shaped so that strains produced by clamping would not propagate down the long "neck" of $\mathrm{Si}$ and cause unwanted and uncontrolled distortions in the bottom horizontal section on which measurements were taken. This arrangement precluded cleaning the sample by resistive heating. Instead we chose to heat radiantly, by immersing the sample in an oven made from a 0.0005 -in. Ta ribbon, $0.5 \times 6$ in. $^{2}$ long, that was resistively heated. The sample temperature could not be determined directly during heating in the "toasterlike" oven, but the ribbon temperature was monitored with an optical pyrometer. It was a straightforward procedure to relate this temperature to those required to effect wellknown surface phase transformations. For example, clear, sharp $7 \times 7$ LEED patterns were seen on both sides of the newly Shiraki-etched sample after heating it for $50 \mathrm{sec}$ using a ribbon temperature of $1500^{\circ} \mathrm{C}$, indicating a sample temperature of $800-900^{\circ} \mathrm{C}$. During this procedure the pressure in the UHV chamber rose to $6 \times 10^{-9}$ Torr and recovered to $3 \times 10^{-10}$ Torr after 10 $\min$.

Gallium was deposited on one of the clean $\mathrm{Si}(111)$ $7 \times 7$ surfaces of the sample from an effusion cell operating at $700^{\circ} \mathrm{C}$ (the sample was not heated during the deposition). The $7 \times 7$ LEED pattern was replaced by a $6.3 \times 6.3$ LEED pattern ${ }^{14}$ with considerable diffuse scattering. The sample was then heated in the oven at progressively higher temperatures until a sharp $\sqrt{3} \times \sqrt{3}$ $R 30^{\circ}$ diffraction pattern, ${ }^{15}$ associated with $\frac{1}{3}$-monolayer (ML) Ga coverage, appeared on the central $1.58 \mathrm{~cm}$ of the sample (the other side remained completely $7 \times 7$ ). A sharp transition to the $7 \times 7$ appeared on both ends of this surface due to a temperature gradient across the sample. Only the central $1.58 \mathrm{~cm}$ of the sample contributes to the bending. Using Eq. (1), we obtain a surface-stress difference of

$$
\sigma(7 \times 7)-\sigma\left(\sqrt{3} \times \sqrt{3} R 30^{\circ}\right)=1.02 \mathrm{eV} /(1 \times 1 \text { cell }) .
$$

Stress differences in the $\approx 1 \mathrm{ML} \mathrm{Si}(\mathrm{Ga})$ (111) superlattice structure ${ }^{16}$ were measured in a similar way. Gallium was deposited and the sample heated until a sharp LEED pattern was observed, containing the $6.3 \times 6.3$ and $6.3 \sqrt{3} \times 6.3 \sqrt{3} R 30^{\circ}$ spots associated with this surface. ${ }^{14}$ A larger stress difference,

$$
\sigma(7 \times 7)-\sigma(\text { superlattice })=1.47 \mathrm{eV} /(1 \times 1 \text { cell }),
$$

was observed. Coverage was later measured on this sample (after reproducing this superlattice diffraction pattern) using standard Rutherford backscattering spectroscopy techniques and was found to be $1.08 \pm 0.07 \mathrm{ML}$ $\mathrm{Ga}$. The stress measurements were repeated with the gallium-adsorbed side cleaned and returned to a $7 \times 7$ reconstruction by heating (for $1 \mathrm{~min}$ with the Ta-ribbon temperature $1300^{\circ} \mathrm{C}$ ) and $\mathrm{Ga}$ evaporated on the opposite face. While the LEED pattern was similar to the previous one, a slightly smaller stress difference, 1.28 $\mathrm{eV} /(1 \times 1$ cell $)$, was measured. It is possible that this weakening of the effect could have been the result of an imperfect replication of the coverage and structure of the $\mathrm{Si}(\mathrm{Ga})$ overlayer. The $\mathrm{Si}(\mathrm{Ga})$ superlattice system is complicated, ${ }^{16}$ and it may not be possible to characterize it accurately without resorting to scanning tunneling microscope, or possibly quantitative LEED, analysis.

We note that, during the course of these experiments, additional stress measurements were taken with equal amounts of gallium on both sides of the sample. Measurements were also taken before and after heating a clean sample (both sides $\mathrm{Si} 7 \times 7$ ) with a ribbon temperature of $1000^{\circ} \mathrm{C}$. No measurable stress difference was induced in either case.

The atomic geometry of the $\mathrm{Si}(\mathrm{Ga})(111) \sqrt{3} \times \sqrt{3}$ $R 30^{\circ}$ reconstruction is fairly well understood experimentally, ${ }^{17}$ and the equilibrium stress in this surface is estimated by LDA calculations ${ }^{6}$ to be

$$
\sigma\left(\sqrt{3} \times \sqrt{3} R 30^{\circ}\right)=1.35 \mathrm{eV} /(1 \times 1 \text { cell }) .
$$

Since the $\mathrm{Si} 7 \times 7$ and the $\mathrm{Si}(\mathrm{Ga})$ superlattice surfaces are too complicated for their stresses to be calculated currently using LDA, we will use the theoretical value for $\sigma\left(\sqrt{3} \times \sqrt{3} R 30^{\circ}\right)$ as a reference from which to gauge the stress in these surfaces. On this basis, we conclude from our data that

$$
\sigma(7 \times 7)=2.37 \pm 0.15 \mathrm{eV} /(1 \times 1 \text { cell }),
$$

and

$$
\sigma(\text { superlattice })=1.0 \pm 0.25 \mathrm{eV} /(1 \times 1 \text { cell }) .
$$

We ascribe the spread in $\sigma$ (superlattice) values to varia- 
tions in surface preparation $( \pm 0.1 \mathrm{eV})$, uncertainties in the optical measurements $( \pm 0.05 \mathrm{eV})$, and our confidence in the LDA calculations for $\sigma\left(\sqrt{3} \times \sqrt{3} R 30^{\circ}\right)$ $( \pm 0.1 \mathrm{eV})$, whereas the spread in $\sigma(7 \times 7)$ is dominated by the latter two.

A theoretical estimate for $\sigma(7 \times 7)$ can be obtained by assuming one can linearly add the individual stress contributions from the various subunits found in the dimeradatom-stacking fault (DAS) model for the $\mathrm{Si}(111)$ $7 \times 7$ structure. $^{18}$ This yields

$$
\sigma_{\mathrm{DAS}}(7 \times 7)=\sigma_{f} / 2+\left(42 \sigma_{p}+9 \sigma_{d}+\sigma_{c}\right) / 49,
$$

which is adapted from Eq. (1) of Ref. 19. Here, $\sigma_{d}$ and $\sigma_{c}$ are the stress contributions to $\sigma(7 \times 7)$ per dimer and per corner hole, respectively. $\sigma_{p}$ is the stress associated with the $2 \times 2$ adatom-covered islands, and $\sigma_{f}$ is the stress due to faulting in one-half of the $7 \times 7$ unit cell. ${ }^{20}$ Using

$$
\begin{aligned}
& \sigma_{p}=\sigma(\text { unfaulted } 2 \times 2)=1.66 \mathrm{eV} /(1 \times 1 \text { cell }), \\
& \sigma_{f}=\sigma(\text { faulted } 2 \times 2)-\sigma_{p}=0.23 \mathrm{eV} /(1 \times 1 \text { cell }),
\end{aligned}
$$

obtained from LDA calculations, ${ }^{5}$ together with

$$
\sigma_{d}=5.1 \mathrm{eV}, \quad \sigma_{c}=4.2 \mathrm{eV},
$$

obtained from Keating-model calculations, ${ }^{19}$ we estimate

$$
\sigma_{\text {DAS }}(7 \times 7)=2.56 \mathrm{eV} /(1 \times 1 \text { cell }),
$$

which is remarkably close to the experimental value we have obtained.

LDA calculations of the stress in a 1-ML coverage, commensurate $\mathrm{Si}(\mathrm{Ga})(111) 1 \times 1$ surface have also been made, yielding an enormous compressive stress of -4.45 $\mathrm{eV} /(1 \times 1$ cell $){ }^{6}$ However, it is somewhat misleading to compare this value to our measured stress in the $\mathrm{Si}(\mathrm{Ga})$ superlattice, as the latter has undergone a radical relaxation and reconstruction from the simple $1 \times 1$ termination to relieve the compressive stress. ${ }^{16}$ The commensurate $\mathrm{Si}(\mathrm{Ga}) 1 \times 1$ structure does not appear to exist in nature. Nevertheless, we are surprised that our measurements indicate a tensile surface stress in the superlattice. It is conceivable that the $\mathrm{Si}(\mathrm{Ga})$ double layer is only weakly bound to the substrate, and that the surface stress is that of the Si substrate with an effectively decoupled overlayer. However, we have no definitive explanation for the sign of the stress at this time.

There are several possible explanations for the discrepancy between theoretical and experimental values for $\sigma(7 \times 7)$. First, the accuracy of the theoretical estimates for $\sigma_{\text {DAS }}(7 \times 7)$, particularly the Keating-model estimates for dimer and corner-hole stresses, is still in doubt. In addition, it is possible that the $\mathrm{Ga}$ coverage on the surface on which the $\sqrt{3} \times \sqrt{3} R 30^{\circ}$ diffraction pattern was observed may not have been uniformly $\frac{1}{3} \mathrm{ML}$, although we saw no evidence of $7 \times 7$ or $6.3 \times 6.3$ diffraction patterns coexisting with the $\sqrt{3} \times \sqrt{3} R 30^{\circ}$. Fi- nally, it may be possible that some in-plane relaxation of the stress is occurring at atomic steps or other surface defects, effectively "screening" the surface stress from the bulk. It may be possible to demonstrate the screening by steps, if it exists, by performing experiments on vicinally cut samples. We anticipate that future refinements in the experimental technique we have presented, together with improvements in the calculations, will clarify these points.

The above analysis depends on the $\mathrm{Si}(\mathrm{Ga})$ (111) $\sqrt{3} \times \sqrt{3} R 30^{\circ}$ as a good fiducial surface. It is clear that the fiducial surface should be well characterized and understood both experimentally and theoretically. In the preliminary measurements reported here we were guided by theoretical estimates to pick a fiducial surface that resulted in a large experimental signal for $\sigma(7 \times 7)$. A better understood surface is $\mathrm{Si}(\mathrm{As})$ (111) $1 \times 1,{ }^{21,22}$ but it should yield a smaller experimental signal for $\Delta \sigma$, from which $\sigma(7 \times 7)$ is obtained. The LDA calculated stress of the $\mathrm{Si}$ (As) $1 \times 1$ surface is $2.27 \mathrm{eV} /(1 \times 1$ cell $){ }^{6}$ and we believe that this value may be more reliable than the calculated value of $\sigma\left(\sqrt{3} \times \sqrt{3} R 30^{\circ}\right)$ for $\mathrm{Si}(\mathrm{Ga})$ $\sqrt{3} \times \sqrt{3} R 30^{\circ}$. We intend to perform measurements using this surface as a reference in the near future.

In conclusion, we have made measurements of surface-stress changes resulting from monolayer and submonolayer coverages of gallium on $\mathrm{Si}(111)$, and have used LDA calculations of stress in the $\mathrm{Si}(\mathrm{Ga})$ (111) $\sqrt{3} \times \sqrt{3} R 30^{\circ}$ surface to make the first determination of stress in the $\mathrm{Si}(111) 7 \times 7$ and $\mathrm{Si}(\mathrm{Ga})$ superlattice surfaces. We suggest that, with some refinements, our technique will be a powerful tool in the study of atomic forces at crystal surfaces and interfaces.

This work was stimulated by the theoretical studies of crystal surface stress undertaken by Professor David Vanderbilt and Robert Meade, and we have benefited greatly from their advice and insight. We would also like to thank J. R. Patel, John Chervinsky, Klaus Mortensen, Dongmin Chen, and the members of the Rowland Institute for discussions and technical assistance. We are grateful to the Harvard University Materials Research Laboratory for providing financial support for this project, under National Science Foundation Grant No. DMR-86-14003. In addition, R.M. acknowledges support from Harvard University, and from the Joint Services Electronics Program of the U.S. Department of Defense, under Contract No. N00014-89-J-1023.

\footnotetext{
${ }^{1}$ H.-J. Gossmann, J. C. Bean, L. C. Feldman, E. G. McRae, and I. K. Robinson, Phys. Rev. Lett. 55, 1106 (1985).

${ }^{2}$ K. Nakagawa, P. M. J. Maree, J. F. van der Veen, and R. M. Tromp, in Proceedings of the Eighteenth International Conference on the Physics of Semiconductors, edited by $\mathrm{O}$. Engström (World Scientific, Singapore, 1987), p. 93.

${ }^{3}$ F. K. Men, W. E. Packard, and M. B. Webb, Phys. Rev. Lett. 61, 2469 (1988).
} 
${ }^{4}$ R. D. Meade and D. Vanderbilt, Mater. Res. Soc. Symp. Proc. 141, 451 (1989).

${ }^{5}$ R. D. Meade and D. Vanderbilt, Phys. Rev. B 40, 3905 (1989).

${ }^{6}$ R. D. Meade and D. Vanderbilt, Phys. Rev. Lett. 63, 1404 (1989).

${ }^{7}$ A. E. Ennos, Appl. Opt. 5, 51 (1966).

${ }^{8}$ P. A. Flinn, D. S. Gardner, and W. D. Nix, IEEE Trans. Electron Devices 34, 689 (1987).

${ }^{9}$ E. Kobeda and E. A. Irene, J. Vac. Sci. Technol. B 6, 574 (1988).

${ }^{10}$ A. Ishizaka, N. Nakagawa, and Y. Shiraki, in Proceedings of the Second International Conference on Molecular Beam Epitaxy and Related Clean Surface Techniques (Japan Society of Applied Physics, Tokyo, 1982), p. 183.

"Silicon Detector Corp., Model No. 380-23-21-051.

${ }^{12}$ See, for example, L. D. Landau and E. M. Lifshitz, Theory of Elasticity (Pergamon, Oxford, 1975), 2nd rev. English ed. Note that the condition for validity of this expression is $L \Delta \theta$ $\ll h$. In our case, $L \Delta \Theta \approx 10^{-4} \mathrm{~cm}$ and $h=10^{-2} \mathrm{~cm}$.

${ }^{13}$ W. A. Brantley, J. Appl. Phys. 44, 534 (1973).

${ }^{14}$ M. Otsuka and T. Ichikawa, Jpn. J. Appl. Phys. 24, 1103 (1985).
${ }^{15}$ J. J. Lander and J. Morrison, Surf. Sci. 2, 553 (1964).

${ }^{16}$ D. M. Chen, J. A. Golovchenko, P. Bedrossian, and K. Mortensen, Phys. Rev. Lett. 61, 2867 (1988).

${ }^{17}$ J. Zegenhagen, J. R. Patel, P. E. Freeland, D. M. Chen, J. A. Golovchenko, P. Bedrossian, K. Mortensen, and J. E. Northrup, Phys. Rev. B 39, 1298 (1989).

${ }^{18} \mathrm{~K}$. Takayanagi, Y. Tanishiro, M. Takahashi, and S. Takahashi, J. Vac. Sci. Technol. A 3, 1502 (1985).

${ }^{19}$ D. Vanderbilt, Phys. Rev. B 36, 6209 (1987).

${ }^{20}$ The interpretation of Eq. (2) is straightforward. The surface stress per $7 \times 7$ cell includes the stress in the triangular adatom-covered islands, whose total area is $421 \times 1$ cells, plus contributions from the nine dimers and one corner hole of the DAS $7 \times 7$ structure. In addition, there is an added stress $\sigma_{f}$ in the faulted half of the DAS unit cell. Note that the strain derivatives of dimer and corner-hole energies discussed in Ref. 19 contribute to the trace of the surface stress tensor $\sigma_{i j}$. Since the stress is isotropic, these strain derivatives are equal to our values for $2 \sigma_{d}$ and $2 \sigma_{c}$, respectively.

${ }^{21}$ J. R. Patel, J. A. Golovchenko, P. E. Freeland, and H.-J. Gossmann, Phys. Rev. B 36, 7715 (1987).

${ }^{22}$ R. S. Becker, B. S. Swartzentruber, J. S. Vickers, M. S. Hybertsen, and S. G. Louie, Phys. Rev. Lett. 60, 116 (1988). 